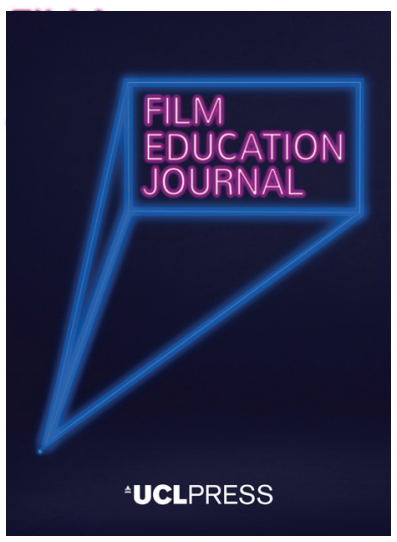

UCLPRESS

FILM EDUCATION JOURNAL

ISSN 2515-7086 (Online)

Journal homepage:

https://www.uclpress.co.uk/pages/film-education-journal

\title{
Film education in a migration society: A conversation
}

\author{
Alejandro Bachmann (D, Christine Kopf (iD) and Manuel Zahn (D)
}

\section{How to cite this article}

Bachmann, A., Kopf, C. and Zahn, M. (2021) 'Film education in a migration society: A conversation'. Film Education Journal, 4 (1), 14-28. https://doi.org/10.14324/FEJ.04.1.02

Submission date: 14 August 2020

Acceptance date: 13 November 2020

Publication date: 10 June 2021

\section{Peer review}

This article has been peer-reviewed through the journal's standard double-blind peer review, where both the reviewers and authors are anonymized during review.

\section{Copyright}

(c) 2021 Bachmann, Kopf and Zahn. This is an open-access article distributed under the terms of the Creative Commons Attribution Licence (CC BY) 4.0 https://creativecommons.org/licenses/ by/4.0/, which permits unrestricted use, distribution and reproduction in any medium, provided the original authors and source are credited.

\section{Open access}

The Film Education Journal is a peer-reviewed open-access journal. 


\title{
Film education in a migration society: A conversation
}

\author{
Alejandro Bachmann - Teacher, writer, curator, Vienna, Austria \\ Christine Kopf - Deutsches Filminstitut \& Filmmuseum, Frankfurt, Germany \\ Manuel Zahn* - University of Cologne, Germany
}

\begin{abstract}
In May 2020, during the lockdown in Germany and Austria due to the coronavirus pandemic, Manuel Zahn arranged to have an email conversation with Christine Kopf and Alejandro Bachmann. Since 2017, both have been a part of the project Intercultural Film Education, which is the central concern of the email exchange. Since the beginning of 2019, Manuel Zahn and his co-researcher Katja Lell have been involved with this project in the form of action research. The project has brought together people and institutions from the German-speaking field of film education, and it aims to foster an intercultural sensibility within that field. The conversation provides information about the history of the project and the project partners, as well as about the forms of work as a learning group. In addition, it discusses the central concepts (intercultural attitude, for example) and objectives of the project. This encompasses and touches upon ideas such as adopting an intercultural attitude as a teacher, the selection of films, the concrete form of seminars, the negotiation of normative concepts and the sustainable structural change of institutions in cultural education.
\end{abstract}

Keywords: advanced training, film education, interculture, intercultural attitude, migration society, professionalization

At the beginning of May 2020, during the lockdown in Germany and Austria due to the coronavirus pandemic, Manuel Zahn arranged to have an email conversation with Christine Kopf and Alejandro Bachmann. They are both part of the project Intercultural Film Education, which is the central concern of this email exchange.

The project has been trying to theoretically rethink and change the way in which film education is practised by the four institutions involved by looking at their own practice from an intercultural perspective. Thus, it is part of an increasing number of projects in the cultural education sector which have begun to implement an inclusive perspective in their practice since the beginning of the twenty-first century. It is based on a self-understanding and a concept of society in which the presence of migrants and migrational movements is neither marginal nor temporary, but constitutive of a social reality that can be called 'migration society'. The public discourses, political debates and disputes of recent years indicate that migration has become one of the most important concepts of social selfunderstanding of the present and the future. Against this background of current social and cultural transformation dynamics, and the fact that Austria and Germany can be understood as migration societies, the question of an intercultural approach becomes urgent in the discourse of cultural education, and thus also of film education.

From a critical perspective, the broader sector of cultural education is complex and contradictory. It promises many positive effects, such as cultural participation, 
personality development, the increase of learning and problem-solving abilities, and the ability to deal with difference. The discourse of cultural education legitimizes itself as an enabler of political empowerment, individual development, collective participation and social cohesion. However, studies critical of power show that cultural education produces exclusion and relations of domination and submission. It can be a tool for social differentiation and elitist selection, for disciplining and conformity.

Facing these contradictions, there is no neutral ground from which to work at the intersection of education and film. In order to deal with the contradictions, one needs to apply a critical attitude which is sensitive to structural forms of discrimination and, at the same time, promotes structural changes in the field of film education. Only then can we reach a state where individuals and groups previously under-represented are supported to work in this field, and to research and shape it.

In order to support this process in the German-speaking countries, the art and cultural educator Carmen Mörsch (2018) has introduced the notion of discrimination critique into cultural education. She developed this concept in relation to Melissa Steyn's (2007) 'critical diversity literacy'. The fundamental difference between the concept of discrimination critique and other concepts such as diversity, plurality, inclusion and integration is a shift in perspective: it asks less about how those who are othered by in this case, Austrian/German - society are 'won' for cultural education, but rather focuses on people working in cultural education, their own position (as an individual, a team, an institution) in a social sphere and their respective power effects, as well as the resulting structural discrimination. According to Mörsch (2018), a successful implementation of critical perspectives into cultural education involves an examination of three intertwined dimensions which are also effective at the intersection of film and education: structures, methods and the canon.

At the structural level of institutions, the following questions arise: What structural conditions would be required in film education so that cultural relations of dominance and violence are not reproduced but interrupted, criticized and, in the best case, changed? What kind of working conditions does one need in order to develop an intercultural attitude in film education? And what are the structural goals to be pursued in the institutions of film education?

From the perspective of the canon, a concept of intercultural film education must address the consequences that an intercultural perspective brings to the idea of content, that is, the selection of films for cultural education. In cultural education, canonization is one of the most important means of establishing and maintaining cultural identity. A critique of the canon can take place in various ways, some of which complement, overlap or at least do not exclude each other: (1) critically reading and appropriating the existing canon; (2) expanding the existing canon; (3) creating other, alternative canons; and (4) fundamentally rejecting the concept of the canon.

In the area of methods, we have to ask what consequences an intercultural and discrimination-critical perspective will have on the methods used in film education. This involves at least two methodological dimensions: on the one hand, how an intercultural attitude shapes the pedagogical situations (such as a training session, seminar or class) themselves, and, on the other hand, how pedagogical situations encouraging a successful intercultural film education practice can be brought about in the first place.

Against the background outlined here, the email conversation had the aims above all - of discussing the concept of an intercultural attitude at the very heart of the project Intercultural Film Education, and showing how the dimensions that Mörsch (2018) identifies are addressed in practice. 
Manuel Zahn: You are both part of the project Intercultural Film Education, which has brought together a number of people and institutions from the Germanspeaking field of film education, and which aims to foster an intercultural sensibility within that field. Before we go into any detail, could you start by telling us about the very first ideas and how the project came about, as well as how both of you are involved in it?

Christine Kopf: As is often the case with these kinds of projects, I have to go back quite a bit for that. For the Deutsches Filminstitut \& Filmmuseum's (DFF) film education department, the starting point for this project was a film club which we founded on the initiative of Vanessa Aab in 2015. Like many other cultural institutions at the time, we wanted to do something for young people who have just completed a dramatic, stressful flight to arrive in Germany. The programme we initiated back then Blickwechsel Jetzt! (Change of Perspective, Now!) - still takes place once a month on Monday evenings. When the museum is closed, young people from a Frankfurt school and from the Kolpinghaus (where a housing project for so-called 'unaccompanied minor refugees' is located) come, have dinner together and watch a film in our cinema. A lot of questions arose from critically reflecting on our format; many of them were linked to the power relations inherent in such a situation.

Katrin Willmann from the Bundeszentrale für politische Bildung (Federal Agency for Civic Education) then gave the impetus for a joint conference which took place in Frankfurt in autumn 2016. The conference, which was called 'Film, Flucht und Interkultur' ('Film, flight and interculture'), was to serve as a platform for critically questioning the many film education projects linked in one form or another to the arrival of migrants, which were often developed very quickly and which always - explicitly or implicitly articulated something political. At the conference, it was important to us to re-establish not a speaking 'about' but a speaking 'with' the people these programmes were originally aimed at, and not to reduce individuals to a single experience within their lives. Since I knew Alejandro's work, and also his guts to address things, I invited him as a moderator. The project we are talking about emerged from this.

Alejandro Bachmann: It might be important to add - because it establishes a certain perspective on how this project came about - that I was sceptical when Tine first asked me to participate in the conference. As a lot of my educational work to that point had been aiming to take film itself seriously as a unique expression to think about the world, the fear was that this was a project where film served as a tool to talk about other things - film as a gateway for certain topics, in this case migration. But I quickly understood that what Tine was looking for was to pose the question of how we can speak about cinema as an art form, and at the same time speak about its potentials to reflect on the political and social realities we live in. In a way, this was a game changer for me personally, because film educational discourses always seemed to be divided into one or the other, and since the aesthetic approach was the one that interested me, and at the same time the one that was practised less, I always wanted to make sure we focused on this aspect. The conference gave me a very strong idea of how we can speak about both at the same time.

MZ: I will come back to the concept of intercultural film education and its perspectivation, which has just come up, at a later stage. Could you please describe to me how the project took shape, and who - which institutions and individuals - are involved and how? 
CK: As I recall, we all noticed at the conference that there is a need to continue working here, to apply the questions that have emerged to our everyday practice, to all our practices, even to the structure of our institutions - it was necessary to react to the fact that our countries have been shaped by migration for decades, but that very few of the educational parameters according to which we work actually take that aspect into account. Thus, in November 2017, the Federal Agency for Civic Education invited us and others to a workshop in Berlin, where facilitators from the film education scene discussed what should be done and what such a project should look like.

The Federal Agency for Civic Education, VISION KINO, the Austrian Film Museum, and the DFF finally joined together in a project group - this in itself is quite a process, even though it is only the starting point - and were joined by a number of freelancers. We have been working on this process-oriented project since the beginning of 2019 . The DFF is coordinating it, and you, Manuel, the Chair for Aesthetic Education at the University of Cologne, together with Katja Lell, are providing research accompaniment with the approach of action research. ${ }^{1}$ The project group now also includes 'critical friends' to ensure that we are able to discuss things from a variety of perspectives - a central step for me.

MZ: There is an implication in your answer that I would like to follow up on. What we have here is a relatively large project with very different partners: a federal agency, two film museums, and a film and media network, as well as a number of individuals who do not belong to any of the institutions mentioned. I would be interested to hear how you organized your collaboration and how a concept was then developed that all project partners agreed on. This then would also have to include a first definition of what you mean by an intercultural film education?

CK: Responsibilities within the project were set down in writing in a jointly drafted cooperation agreement, as well as the resources that each institution can contribute. The main part is funded by the Federal Agency for Civic Education, but all others also invest. As a very first step, the group commissioned an author, Alejandro, to further develop what had been discussed in the group until then into a written concept.

AB: The concept was about fifty pages long and consisted of a number of parts. The first one tried to define what we mean by an intercultural film education. Boiled down, I think it is safe to say that it means to establish a practice of film education that pays tribute to the fact that we live in a migration society. This asks that we reflect on the way we teach film, the way we address students, and the way we choose films, but it also asks us to reflect on the way we use language in teaching materials, the hiring policy in institutions and things like this. Last but not least, it also means to reflect on who 'we' actually are? Who is present as a teacher or as a facilitator in film education? So, when you asked about our definition of 'intercultural film education', all of these elements are concerned. Once we move a bit closer to the films themselves and the practices of teaching them, we tried to propose an aesthetic approach to cinema which makes use of the experience of watching a film to reflect on how we encounter others, and how perspective shapes perception.

There is one sentence by Paul Mecheril (2015) that I feel is quite central to how we approach the whole topic. He says that aesthetic experiences allow us to perceive, and to perceive that we perceive. This, I feel, is the core of the concept. We do not want to use film to talk about a migration society, we want to experience films in order to reflect on the experience of living in a migration society, and its implications for 
the fields of politics and aesthetics. Thus, the concept also entails two propositions for training that can serve as a first step towards what we would call an intercultural attitude. I have to add: the German-language concept talks of 'Haltung', which can be translated both as attitude and stance.

CK: To steer the cooperation, the DFF has a project coordinator, Sebastian Rosenow, who keeps the group together by inviting people to telephone conferences or real meetings, preparing the agenda, writing minutes and sending regular reports on the project status - but, of course, also discussing the content, commissioning authors and critical friends, and so on. We have a lot of telephone conferences with the Federal Agency for Civic Education to prepare decisions. Two other colleagues are active: Miriam Reichert is responsible for organizing the training courses in advance and on site, and Antje Knapp is in charge of editing the texts to be published online. Central to the development of the project was the fact that Katja Lell and Manuel introduced so-called 'reflection meetings' after the concept had been evaluated, in which we jointly decided on new concrete actions after reflecting on each training course, and we were thus in a permanent transparent learning process as a group.

MZ: I would like to follow up on this term: 'intercultural attitude'. I have understood that it is an attitude, which is to be expressed in all practices in the field of film education (language, methods, teaching materials, film selection) as well as on a structural level (in the hiring policies of institutions). So what exactly do you mean by the term 'interculture'? And how does it relate to the concept of migration society (Migrationsgesellschaft), a term coined by Paul Mecheril (2004) and others?

$A B$ : Maybe it is best defined by stating what it is not: an intercultural pedagogy does not try to address any specific 'Other', but rather thinks of a society in which everyone is potentially someone's 'Other'. This also means to step away from any notion that there is a form of culture that is dominant and to which some people have to adapt, while others are already part of it. The idea of an intercultural pedagogy is not to help people compensate for a deficit - be that language skills or knowledge about traditions. Questions of nationality and ancestry do not really matter all that much, but it is rather cultural contexts which are put into focus. Thus, what an intercultural attitude longs for is an attitude towards others and society as a whole where encounters between cultural contexts and different perspectives to think about and see the world are made possible. The idea is to reflect on identity as something that is in constant flux and that has to be negotiated.

All of these elements led us to emphasize that what we are suggesting with an intercultural film education cannot be understood as a certain set of skills that can be acquired, but rather a certain attitude, a stance, if you will, that allows you to constantly negotiate and re-negotiate who you are, how you perceive the world, how you perceive others. Framing it in such a way might articulate quite well how an intercultural pedagogy and an interest in film education might complement each other.

CK: For me personally, the discovery of Paul Mecheril's (2004, 2015, among others) and Mark Terkessidis's (2010) texts in 2016 was important, also as a complement to Alain Bergala's The Cinema Hypothesis (2016), because they draw attention to power relations within any educational setting. Our field, from film history to today's film production and distribution, is deeply influenced by colonialism and Eurocentrism. I find the approach of consistently thinking of the common migration society as the 
starting point of all practices productive - in contrast to repeating the pattern of 'we' and 'them' again and again. I am very tired of people with a migration biography being treated as those who carry a deficit. I find it so much more inspiring to include their perspective, their experience and their knowledge in thinking about all of us. This conviction might be a first step. However, I also feel that this attitude must be practised in everyday life. Rebuilding cultural institutions is a very laborious and demanding task; we use projects such as this as an impulse to at least scratch at encrusted structures. Thus, our term 'interculture' may encompass elements which, in an academic context, might also be referred to as 'transculture', and which is widely considered to be more progressive. The transformation of the attitude of a whole institution takes time, and we feel that it is easier not to go into these detailed differences between certain concepts of framing a migration society at this very moment.

MZ: Thank you for your insightful remarks, which make it seem almost inevitable for me to speak of an intercultural attitude. Alejandro, you framed your answer by establishing a relationship between an intercultural pedagogy and an interest in film education, and stated how they could complement each other. And at the beginning of the discussion, you emphasized an aesthetic approach to film education, and I know that you also work with this approach when you teach film. Could both of you please explain in more detail why, and in which way, aesthetic film education is suited to develop such an intercultural attitude, or at least to make people sensitive to such an attitude?

AB: I think there is a certain relationship between how we experience aesthetics and how we perceive another person. Maybe this relationship could be described through the ideas of 'encounter', 'perspective' and 'framing'. Watching a film can be an encounter in a sense that it establishes a constellation which happens between me and an other, a certain aesthetic that allows me to look at the world differently, an encounter that actually changes my perspective, and thus changes who I am. It does so by framing the world in a certain way, through the aesthetic means at its disposition. Because the way the world is framed is something that is not me, that is outside myself, a film enables me not only to have a different perspective on the world, but also to reflect on how this different perspective is brought into existence: what is it in the film and what is it 'inside' me (the images I have seen, the clichés I have internalized, the unconscious bias I carry with me) that makes me take over a certain perspective? Ideally, every new film can be another small step in an ongoing process of encountering new perspectives and reflecting on their specific quality. If we translate this process to existing in a migration society, the relationship becomes quite clear: I encounter people, I acquire and change perspectives and I am allowed to reflect on this process - why my experience of an encounter might differ from another person's. It is precisely because aesthetics are a way of framing a world, and allowing me to reflect on how they frame it, that can help me to understand that these processes also happen outside a cinema. An intercultural pedagogy to me would try to establish this as an ideal - that you do not take your perspective for granted, but understand how that specific perspective is shaped, and thus accept that it could just as well be otherwise. An intercultural film education would try to shape ongoing and open-ended dialogues, between the film's perspectives and the perspectives on films.

CK: Aesthetic education in general has had a focus on cultural participation in the international, but also in the German, discourse in recent years - and thus, of course, 
the migration society also comes into view. In this context, there have been a number of discussions and publications about approaches critical of discrimination, on the decolonization of museums and archives, and so on. But to my knowledge, this has not been widely received in German-language film education. In our work at the DFF, we also choose the approach of aesthetic film education - teaching film as shaping an experience and emphasizing that process - as a counterbalance to the competenceoriented school system. For us, it is important to create situations in which young people can let themselves be touched by film as art, to have an encounter. If, for example, one selects films in advance for school screenings based on key words such as 'Islamism', 'terrorism' or even 'flight', and thus arrives at a certain selection and type of film - then films can also reinforce stereotypes, and further discriminate against people in the cinema auditorium, and the important social discussion (as an encounter of perspectives) that would be possible in the cinema is nipped in the bud. We have a huge responsibility here. In aesthetic education, too, we are by no means immune to unreflected steps; it remains a permanent learning process, but through the project, we try to foster an approach which is shaped by a shared desire for openness, challenging encounters and multiperspectivity.

MZ: What you describe here, I feel, is that the project also includes a certain process of 'unlearning', to use a term coined by the postcolonial theorist Gayatri Chakravorty Spivak (1996), and it needs a corresponding will and a constant sensitivity to discrimination in order to introduce an intercultural attitude at all levels of film education. We have talked about the theoretical idea; now let's be very concrete: how are you trying to implement this intercultural film education - for example, in these trainings in the context of the project, which Alejandro mentioned earlier? Or can you think of another suitable example that could be used to further explain your approach?

AB: The concept I have written on the basis of the whole group's discourse on the topic includes the outline of an advanced training in two parts - one for film educators and teachers (entitled 'Encounter'), and one for people conceptualizing and writing educational materials (entitled 'Perspective'). While they are aimed at these specific groups within the field of film education, they actually complement each other. The basic idea in both of them is to look at specific excerpts of film and to begin to understand how every film shapes encounters and perspectives, and how this connects to a migration society. In the beginning, we try to stay very close to the experience of the film and then, little by little, connect our experiences and thoughts with broader topics, such as 'framing', 'othering' and 'stereotyping', or to introduce concepts such as 'migrational knowledge'. So, for example, we would start with an early film by the Lumière brothers to discuss how imperial power structures are visible in a one-minute film itself. Then we could go on to an experimental work such as John Smith's OM (1986) to find out how it is basically impossible for us not to categorize or label someone, and how this process is one that often fails to understand what we see. In a next step, we could look at the first ten minutes of Rainer Werner Fassbinder's Fear Eats the Soul (1974), and discuss how a narrative film establishes our position as a viewer as a space that transcends binary opposites and places us in a liminal space 'in between'. After discussing this work, we might add an excerpt from the documentary My Name Is Not Ali (2011) by Viola Shafik, which looks more closely at the role that El Hedi ben Salem played in the circle around R.W. Fassbinder. Our colleague Irit Neidhardt suggested this addition, and it is a very powerful didactic approach because it connects our perception of a work of art with its production context. This can be a reminder of just how closely we 
have to look to understand power structures and structures of racism, but it also brings us into a situation where we have to deal with the ambivalent relationship between the impact of a work of art and what actually happened to create this impact. We might end this day by watching an excerpt from a documentary film by Kurdwin Ayub, who was born in Iraq and is now living in Vienna. In Paradise! Paradise! (2016), she accompanies her father to visit the Peshmerga in the north of Iraq. It is a very funny, yet also sad and very smart, reflection on what it might mean to live between two cultural contexts, to be neither one nor the other.

So, in a day, we would have encountered early cinema, experimental film, a classic of narrative cinema and a documentary - quite a wide range of what cinema can be. And while we would always start with describing the aesthetic experience, we would also slowly begin to reflect on that aesthetic experience in the setting of a migration society. It is important to note that these concepts are not meant to be blueprints which others who conduct such a training should copy in exactly this way, but they serve as an example of how to frame an intercultural film education which does more than just use the films to talk about larger subjects such as a migration society. The idea is to initiate a conversation between film history, the reality of a migration society and the individual who is intertwined with both of them.

CK: Alejandro and his colleague Martina Döcker also held this training for the members of the DFF's film education department. So, we try to go both ways: reach new people with this project, but also work on our own intercultural attitude within the institutions with which we are entangled. Another important step in the whole process was to include 'critical friends'. People who carry with them a certain kind of situated knowledge, shaped by their own migration experience, should always be present at the training sessions, and they have to be included in the discussion from the start. 'Talking about' has to be replaced by 'talking with', and very quickly one realizes how completely different dynamics result. Another example of how to challenge our own work would be that we asked Alejandro and Martina to discuss in the training a film which we often include in our formats in early childhood education: Les Kiriki by Segundo de Chomón (1907), which is a typical example of an early cinema of attractions. We see a number of people who are disguised to represent people with an Asian appearance performing tricks. We discussed this at the end of the day, which was all about raising awareness and developing a new attitude critical of discrimination. This was a tough, even emotional, discussion, and we became much more aware of our responsibility not to discriminate against young people in the cinema with our film selection - at the same time, we have the task of keeping our film heritage alive. These processes have led to rebuilding parts of the format and revising the materials for educators.

MZ: So your approach to intercultural film education is about reformulating which films we might consider for film education, taking the film experience as a starting point and then dealing with the film's perspectives, as well as the spectator's. It is in this field of tension between perspectives that each individual must position himself or herself, must enter a process of negotiating. This dialogue, which welcomes and even provokes differences, but which is critical of discrimination, needs a diverse group or, to put it in other words, a group of people who represent the reality of the migration society. Accordingly, the concept of an intercultural attitude is a relational and dynamic concept. In the field of encounters described above, attitudes must be found and adopted again and again from new perspectives between films and people, between film history and actual society. All of this seems to be a very dynamic process, a process 
that actually emphasizes that there is no goal to reach and no competence to acquire for good. But speaking from the experiences you have already made, are there some basic rules or conclusions you have taken from it?

AB: I think you already said it: the very idea of the project is to understand yourself - as a teacher, a student, a citizen of the world - in an ongoing process, and that ideally every encounter can lead to a process of interaction, of considering different perspectives, of negotiation. We have found a couple of elements to be essential to initiate these processes. Our training is headed by two people, to instil the idea of dialogue from the start. We have found the presence of our critical friends - people with a migrational background or a lot of experience in these discourses within the cultural field - to be of utmost importance, as they were seminal in unfolding questions and perspectives that we would not have encountered without them. Also, we saw very clearly, that the training became richer, livelier and more progressive whenever the number of people with very diverse biographies and experiences were part of the group. You can do as much as you want, but if you do not increase the presence of difference within the group with which you work, the richness of the potential dialogue which can unfold will not be reached.

CK: In any case, it has become clear to me that once you are on the road in your professional life with such an attitude, a tremendous number of things come up that need to be changed. It is important to tackle one thing at a time, to manage your strengths so as not to give up. These processes are much more strenuous and profound than I might have naively thought at some point. 'White fragility' is a relatively new term for me, but I find myself more and more often in situations that have to do with it.

MZ: OK, I understood the following: as important as these trainings are for the development of an intercultural, discrimination-critical attitude in film education, they are not enough. Changes are needed in all areas and at all levels of film education, and in cultural institutions such as museums, as well as in educational institutions such as schools and universities. The materials and methods of film education must also change, you said earlier. Have you already come up with ideas about how these changes could be supported and initiated?

CK: In fact, at DFF, we're trying to move forward as an institution as a whole. Mark Terkessidis (2010) talks about particularly persistent 'glass ceilings' in cultural institutions. It is not enough to act in temporary projects, or only to conduct training, we have to go to the very structures that define our day-to-day work. Saraya Gomis, who worked as an anti-discrimination delegate for schools in Berlin, suggests that what we need is not only sensitization but professionalization (interviewed by Corinna Koch, 2020). Rethinking and reshaping the institution would be a step in that direction. Most importantly, we have to change the composition of our staff. In parallel, we need to jointly question our programme guidelines and rethink who our audience is and how we reach them. The size of the task should not be underestimated; it also requires additional resources. To start the process, at DFF we have hired two new part-time employees, Aida Ben Achour and Rabih El-Khoury, who have established a crossdepartmental diversity working group that now meets once a month on a voluntary basis, but during working hours. Similar to our project Intercultural Film Education, I perceive that the first step is to develop a common language and culture of discussion. This is always a laborious struggle; institutions have a tendency to remain in the status 
quo. But in the process, we have developed a very important shared common culture of learning and discussion, which we did not have before as a team.

AB: I think, judging from the project so far - from the discussions that have taken place, the training conducted, and the encounters between individuals and institutions it is safe to say that this process of changing all of the film educational parameters in the direction of an intercultural attitude is really quite demanding for everyone involved. There are a lot of reasons for this, and certain traditions and (psychological and institutional) structures that feel like they have always been there, and which feel self-evident, are only one element in this. Another element, I feel, has to do with how we perceive education, what we consider its role to be within a larger context, but also what we define as the purpose of film education. The approach we have taken - combining ideas from migration pedagogy with an aesthetic approach to film education - puts a significant emphasis on processes and dialogue. Knowledge is produced in an ongoing process between people, in a dialogue that also tries to get away from existing hierarchies, between teacher and student, between cultural institution and a politically active individual, between those who know, speak and create meaning, and those who listen, imitate and are seldom heard.

MZ: Could you please elaborate on what you mean by a learning group, and what role your understanding of film pedagogy plays in this? Your last remarks remind me of Jacques Rancière's reflections in The Ignorant Schoolmaster (1991). In it, Rancière suggests a new pedagogical relationship, which is also characterized by a changed attitude towards knowledge. Can you relate to this? What is your understanding of film pedagogy and its purpose, and can you describe more precisely what role which kind of knowledge plays in it? Are we talking about a knowledge of film theory, or a knowledge which is connected to a specific film, or a knowledge of aesthetics and its processes in general, or a knowledge of film history? And where would we situate a knowledge critical of discrimination or sensitive to using non-discriminatory language?

AB: In a more general sense, I would argue that film education is about creating a situation where people relate the emotions and thoughts they have had while encountering a film to the work of art, to themselves and to each other. The conversations that take place are about following your thoughts and making them transparent to others by being precise about exactly what in a film has created your thought or emotion. So, what you do is link a certain experience that is created to a certain form, and you make this perspective available to others and to the discourse. As a film educator, I understand my role to be two things: I want to encourage people to talk about what they think or feel when encountering an artwork, and I urge them to find a language to describe this by staying as close to the film as possible. In that sense, I argue that teaching film (or any art form) may have to do very little with passing on knowledge, but rather about passing on a certain fascination for being involved with art, or letting yourself be touched by art - this, obviously, is very close to what Alain Bergala (2016) means by the concept of the passeur, and what Rancière (1991) says about the attitude of the ignorant schoolmaster.

If we decide to call something in these processes 'knowledge', then I would state that it is a certain kind of implicit knowledge that I as a teacher/educator, but also anybody else talking about the film, always carries around with them. This is why, as Tine has mentioned, it is important to have more people with different migrational contexts enter the discussion, because their knowledge is a migrational knowledge 
that has developed through their experience. This is a kind of knowledge that cannot be acquired willingly, but that one accumulates over time and unintentionally. An intercultural approach to film education would have to do everything at its disposal to make this kind of knowledge heard, to make it an integral part of the discourse. Steps in that direction would be to let go of an understanding of education as a passing on of knowledge from the teacher to the student, or of a cinematographic canon to the next generation, or of certain aesthetic value systems to young people, and instead to emphasize a continuous dialogue that has no final goal, but which continuously creates new positions which, as a whole, create ever-changing patterns or constellations within which we discuss culture. So, Rancière's (1991) concept of the 'ignorant schoolmaster' is very relevant in that respect, especially if we combine it with the idea of 'negotiation', as Homi K. Bhabha (1994) has articulated it with respect to the location of culture. Knowledge about culture is not handed down, is not taught in a classical sense; it is negotiated between a number of people whose unity as a group is defined by difference.

MZ: I very much agree with your remarks on film education and your concept of knowledge. I have also understood that it is important to you in the project to always critically question the constitution of culture in the migration society in the discussion of films, and to consider interculture as a construction, and not to be understood as something unquestionably given. I would like to add that a reflected intercultural pedagogy should also consider influencing factors such as race, gender, social class or age from an intersectional perspective. I emphasize this here because people are never affected by only one isolated form of discrimination, but are always at the intersection of multiple lines of discrimination. Accordingly, an intercultural pedagogy that wants to live up to its name would not have to focus exclusively on migration and cultural differences, but would rather have to take up, address and analyse general cultural differences, their production and changes in social contexts.

Against this background, I would like to go into more detail about the concept of negotiation that Alejandro brings to the table with reference to Bhabha (1994). How exactly is this to be understood in the context of film education? How does one break away from the idea of the encounter of different cultures with more or less potential for conflict? And how does such an understanding relate to a concept of national cinematography, for example, as we find it in film historical discourses and also in museum collection practice?

CK: Carrying the word 'German' in our institution's name already brings to the table some of the questions you have just asked. It implies that we have a national mission as an institution, and that we are actually 'gatekeepers' in matters of a German film history. In this way, our institution produces a relationship between the words 'German' and 'film'. A film's official 'nationality' is determined by a number of criteria, not least of which are funding sources. We in the Education Department also see it as our task to give impulses to the whole institution, to question issues such as this, and to think about things anew. The scholar Naika Foroutan (2019) has defined the people who live in Germany as Germans, and this is an idea that I want to follow. Being situated in Frankfurt, we operate and live in a city where most people have relatives all over the world; the city is extremely diverse. Thus, we have initiated a new project, and we want to create a 'Frankfurt film treasure' that could be understood to be an alternative film canon. We want to ask as many city residents as possible (different in terms of gender, social status, migrational experience and so on) which films we should collect for them, because they have memories of them, and because the films are important to them. 
We want to use this collection of film titles as a starting point for discussions - and, thus, perhaps accentuate our institutional mission anew. In my view, modern cultural institutions have the task of always looking closely at what society needs them for; they need to reinvent themselves.

AB: Yes, it's a good way of triggering a negotiation. It is an institutional practice that calls into question some of its practices connected to the concept of nationality, and offers to redefine what we constitute as our culture of reference. Culture here is not essentialist, but is in a permanent movement of transformation, is something new every time one comes back to refer to it (which basically is the function of a canon). Conflict is a very concrete thing in these processes, because obviously this approach calls into question a lot of things on which people in the cultural sector, as anywhere else, base their ideas, value systems and understanding of culture.

MZ: One can say that you conceptualize interculture and intercultural film education as an invitation to all people of a society to participate in shaping the sociocultural space. In this understanding, film-aesthetic moments of your pedagogical concept touch upon broader normative ideas and values, such as the question of what can be considered socially, politically, culturally and/or ethically desirable. It is perfectly clear that we cannot do justice to this question in the given brevity at this point. But can you please elaborate a bit on how you think about the relationship between the aesthetic and normative dimensions in your pedagogical work?

AB: I think the pedagogical work we are looking for is one that fosters an understanding of how things are shaped, artificially made, constructed, created, if you will, and how these constructions move us, and make us think and feel, about the world and ourselves. Potentially, every aesthetic experience has the potential to change all of these parameters, to move me from a position $A$ to a position $B$, and thus to look at the world anew. Film education in a migration society should strive to put an emphasis on this idea of reshaping our position - by means of a different canon or even concept of a canon, by showing other films and letting other people present programmes, and by teaching differently and letting people with different migrational experience teach. Thinking about implementing an intercultural attitude goes hand in hand with this idea of aesthetic experiences, because here again we try to think about concepts that define our world as constructs - identity, notions of 'the other', belonging - and then reshape them. The normative plays a role in all of this in that we want to question what is considered as the norm, and maybe introduce the idea of negotiation instead. What film education makes possible is to actually experience these new positions, these other constructs, and thus to navigate within them and try yourself out.

CK: Art has the potential to open up spaces of possibility that question normative social orders. This is another reason why it is so important to me to enable young people to encounter it, especially those who are affected by inequality of opportunity. Theoretically, cultural education has the power to make social orders permeable, and thus to change society. This utopia motivates me to examine film education in terms of power relations, and to transform it.

MZ: Do you know of comparable projects, or even individual institutions, in the field of film education on a national and international level which strive for similar structural changes? 
CK: I was impressed by Jyoti Mistry's lecture 'Processes in decolonising film education' at the Scottish International Film Education Conference in June 2020, in which she described her own work with students at the Gothenburg Art Academy. ${ }^{2}$ She has also done a project with students at the Eye Film Archive (Archive as a Place to Play). Apart from that, I do not know of any project specifically related to a country's film education scene, but some film cultural institutions and festivals in Europe are looking at how their institutions can be more diverse. All of them work in a similar direction, although their approaches are very different. The European Film Market of the Berlin International Film Festival is doing this very intensively, and it has hired a coordinator for its diversity and inclusion initiative, Themba Bhebe. He is also a founding member of the international Programmers of Colour Collective (POC2), which aims at creating a conversation around, and at working towards, a more diverse and inclusive programming pool at international film festivals through research, awareness events, networking, profile raising and mentoring. It was founded in January 2019 at the Sundance Film Festival. In Germany, the Düsseldorf Film Museum is part of a diversity process initiated by the city administration. Filmförderung Hamburg has now become the first German state funding agency to come out with a diversity questionnaire.

The British Film Institute has had 'diversity standards' for some time now, covering the following topics: on-screen representation, themes and narratives, creative leadership and project team, industry access and opportunities, and audience development. In autumn 2019, an interesting initiative, co-initiated by the GoetheInstitut at Culturgest in Lisbon, started a multi-part 'Call for action and reflection on decolonizing film archives'. These are the examples I have come across recently, without claiming to be complete, of course.

MZ: I hope that there are more such initiatives and projects in the field of film education, and that there will be even more in the future! You have both repeatedly pointed out that, in the sense of Terkessidis's (2010) programmatic understanding of interculturality, one must leave behind singular, temporary projects in favour of long-term structural changes. At the end of our conversation, I would like to ask about this very level: if you could wish for specific steps to support an intercultural film education on a structural level, what exactly would they be?

CK: What I would like most of all is that in future in Germany, it would no longer be just people with no experience of migration who are almost exclusively active in film education - then everything else would come 'naturally'. Until we reach that point, it would be great to be able to do even more training for facilitators, authors and then also teachers, without having to give up the quality we have now achieved.

AB: Small steps on a more basic level will also have to happen in relation to the understanding of film education that we have. Looking at film teaching materials as just one of many concrete examples - one would have to find a language and a perspective which supports this idea of analysis as a process of forming a dialogue between different experiences. When you compare this to how teaching materials being currently used conceive of teaching, we can get an understanding of how very radical the changes have to be. These changes are not an addition or an amendment to a concept of education already in place, they concern the very core of what we do.

MZ: Thank you for your time and the inspiring conversation. I wish the project a successful completion, and that it will not only be noticed and discussed in the 
German-speaking discourse of film education, but that it will also promote the important structural changes we have talked about.

\section{Notes}

1. This approach follows on from the action research of the 1970s and 1980s, which had prominent advocates - particularly in Great Britain - in Lawrence Stenhouse and John Elliott. This critical research approach resolutely opposes an outcome-based model of teaching and learning and opts - first and foremost - for an improvement of pedagogical practice in an ethical sense. The aim is to include the practitioners in research processes, and thus to create reflexive practitioners who are able to investigate and answer questions about the quality of their own pedagogical practice themselves. 2. This presentation has been written up and can be found in this issue of the Film Education Journal (Mistry, 2021).

\section{Notes on the contributors}

Alejandro Bachmann is a Vienna-based film worker with a focus on teaching and writing about film and curating film programmes (particularly documentary and experimental forms). From 2010 to 2019, he was a research associate and then Head of the Education, Research and Publications Department at the Austrian Film Museum. $\mathrm{He}$ is part of the selection committee for the documentary section of the Diagonale and Duisburger Filmwoche film festivals, and an associate editor of Found Footage magazine and the Film Education Journal. He is currently Visiting Professor for Film History and Media Theory at the Academy of Media Arts Cologne.

Christine Kopf is Head of Film Education and Co-Director of Strategic Development at Deutsches Filminstitut \& Filmmuseum, Frankfurt, Germany (DFF). She has worked for this German cinematheque for more than twenty years, curating exhibitions, programming film series, and organizing special events, including a programme to celebrate its re-opening in 2011. She has also been curator for the Film Prize for International Cooperation for young film-makers from Germany and the Arab world, and Director of the goEast film festival, Wiesbaden.

Manuel Zahn is Professor of Aesthetic Education at the Institute for Art and Art Theory at the University of Cologne, Germany. He studied educational science, philosophy and psychology at the University of Hamburg and received his doctorate with a book on aesthetic film education. He previously worked as Professor of Art Education at the Academy of Fine Arts Brunswick, and as a research assistant at the universities of Oldenburg and Hamburg. His fields of work are philosophy of education, media pedagogy, especially film education, and arts education in digital media culture. His latest book is Education in the Age of the Screen: Possibilities and transformations in technology, edited with Nancy Vansieleghem and Joris Vlieghe (Routledge, 2019).

\section{Filmography}

Fear Eats the Soul (Angst essen Seele auf, DE 1974, Rainer Werner Fassbinder)

Les Kiriki (FR 1907, Segundo de Chomón)

My Name Is Not Ali (EG/DE 2011, Viola Shafik)

OM (GB 1986, John Smith)

Paradise! Paradise! (AT 2016, Kurdwin Ayub) 


\section{References}

Bergala, A. (2016) The Cinema Hypothesis: Teaching cinema in the classroom and beyond. Trans. M. Whittle. Vienna: FilmmuseumSynemaPublikationen.

Bhaba, H.K. (1994) The Location of Culture. New York: Routledge.

Foroutan, N. (2019) Die postmigrantische Gesellschaft: Ein Versprechen der pluralen Demokratie. Bielefeld: transcript.

Koch, C. (2020) 'Es wird schmerzhaft'. Süddeutsche Zeitung, 29 June. Accessed 29 July 2020. www. sueddeutsche.de/kultur/struktureller-rassismus-deutschland-interview-saraya-gomis-1.4946962.

Mecheril, P. (2004) Einführung in die Migrationspädagogik. Weinheim: Beltz.

Mecheril, P. (2015) 'Kulturell-ästhetische Bildung. Migrationspädagogische Anmerkungen'. Kulturelle Bildung online. Accessed 29 July 2020. www.kubi-online.de/artikel/kulturellaesthetische-bildung-migrationspaedagogische-anmerkungen.

Mistry, J. (2020) 'Processes in decolonising film education'. Paper presented at the Scottish International Film Education Conference, 18-19 June 2020.

Mistry, J. (2021) 'Decolonizing processes in film education'. Film Education Journal, 4 (1), 1-13. https://doi.org/10.14324/FEJ.04.1.01

Mörsch, C. (2018) 'Critical Diversity Literacy an der Schnittstelle Bildung/Kunst: Einblicke in die immerwährende Werkstatt eines diskriminierungskritischen Curriculums'. Kulturelle Bildung online. Accessed 29 July 2020. www.kubi-online.de/artikel/critical-diversity-literacy-schnittstellebildung-kunst-einblicke-immerwaehrende-werkstatt.

Rancière, J. (1991) The lgnorant Schoolmaster: Five lessons in intellectual emancipation. Trans. with an introduction by K. Ross. Originally 1987. Stanford, CA: Stanford University Press.

Spivak, G.C. (1996) The Spivak Reader. Eds D. Landry and G. Maclean. New York: Routledge.

Steyn, M. (2007) 'Critical diversity literacy: Essentials for the twenty-first century'. In S. Vertovec (ed.), Routledge International Handbook of Diversity Studies. New York: Routledge, 379-89.

Terkessidis, M. (2010) Interkultur. Berlin: Suhrkamp. 